\title{
Formulation and in Vitro Evaluation of Sustained Release Tableted Microspheres of Gemcitabine
}

\author{
Munagala Gayatri Ramya $^{1^{\star}}$, Rajesh Akki $^{2}$, Singaram Kathirvel ${ }^{3}$ \\ ${ }^{1 *}$ University College of Pharmaceutical Sciences, Acharya Nagarjuna University, \\ Nagarjuna Nagar 522 510, India \\ ${ }^{2}$ Hindu College of Pharmacy, Guntur -522 002, India \\ ${ }^{3}$ National College of Pharmacy, Manassery-P.O, Mukkam, Kozhikode-673602, India
}

\begin{abstract}
Gemcitabine is a nucleoside metabolic inhibitor that exhibits anti tumor activity with half-life of 32-94 minutes for shorter infusions and 245-638 minutes for longer infusions. The aim of the present study was to prepare and evaluate tableted microspheres that are loaded with Gemcitabine using solvent evaporation technique. Ethyl cellulose was used as a drug release retarding polymer. The microspheres were characterized by Fourier transform infrared spectroscopy (FT-IR) to confirm the cross linking reaction and chemical stability of Gemcitabine. The particles are spherical in shape and have smooth surfaces, as evidenced by the scanning electron microscopy. The microspheres were characterized for their particle size and distribution, tapped density, percent yield and encapsulation efficiency and in vitro drug release. The microspheres were directly compressed into tablets using different exipients. The tablets so prepared from these microspheres were evaluated for hardness, friability, weight variation, drug content and in vitro dissolution study.

Keywords: Gemcitabine, microspheres, solvent evaporation, tableted microsphers.
\end{abstract}

\section{Introduction}

Biodegradable microspheres ${ }^{[1]}$ used as controlled release (CR) systems are important in pharmaceutics. The basic idea is to accomplish a drug delivery system with biodegradable microspheres ${ }^{[2]}$ which degrade within the body as a resultof natural biological processes, thereby eliminating the needto remove the delivery system after its function is over. Microsphere carrier systems made from the naturally occurring biodegradable polymers have attracted considerable attention for several years in sustained release drug delivery. Recently, dosage forms that can precisely control the release rates and target drugs to a specific body site have made an enormous impact in the formulation and development of novel drug delivery systems. Microspheres have varied applications and are prepared using assorted polymers. However, the success of these microspheres is limited owing to their short residence time at the site of absorption.

International Journal of PharmTech Research, 2018,11(3): 287-297.

DOI: http://dx.doi.org/10.20902/IJPTR.2018.11310 
Gemcitabine ${ }^{[3-5]}$ is a nucleoside analog used in chemotherapy. As with fluorouracil and other analogues of pyrimidines, the drug replaces one of the building blocks of nucleic acids, in this case cytidine, during DNA replication. The process arrests tumor growth, as new nucleosides cannot be attached to the "faulty" nucleoside, resulting in apoptosis (cellular suicide).

Gemcitabine is used in various carcinomas: non-small cell lung cancer, ovarian cancer, pancreatic cancer, bladder cancer and breast cancer. It is being investigated for use in esophageal cancer, and is used experimentally in lymphomas and various other tumor typescommercially; the drug is available as i.v. infusion due to its short half-life (8-17 min), rapid metabolism and limited tumor uptake. It can be eliminated through urine. Elimination half-life was 32-94 min for short infusions and 245-638 min for longer infusions.

Ethyl cellulose (EC) is a polymer of $\beta$-anhydro-glucose building blocks joined together by acetalbonding ${ }^{[6]}$. It is generally considered as a nontoxic, biocompatible and non-biodegradable polymer ${ }^{[7]}$. EC coated microspheres have also demonstrated their capability to absorb pressure and therefore save the coating from fracture during tablet manufacturing process. This process involves conversion of multi-unit system into a single unit dosage form by compression. This single unit system disintegrates slowly into sub-units when exposed to dissolution process.

Controlled release multiple-unit oral dosage forms are effective in achieving optimal therapy with drugs that have a narrow therapeutic range of blood concentration or that eliminate rapidly and reduce the risk of gastric irritation at one particular site because of the uniform distribution of the drug throughout the GIT. Encapsulation of drugs into polymeric matrix can be achieved by techniques, such as solvent evaporation ${ }^{[8]}$, coacervation $^{[9]}$, spray drying ${ }^{[10]}$, etc. Tableting ${ }^{[11-13]}$ of polymeric microspheres would result in controlled release $^{[14]}$ of the drug. After tableting of microspheres, the particles may remain intact within the tablet without undergoing merging or rupturing and, hence, drug release will take place from the individual microspheres; if not, the microspheres may merge or rupture to become bigger compacts. In such cases, the release will occur from compacts in the tablet formulation. Ideally, the drug release should occur from the individual particles, which should not be affected by the compression process. However, excipients used in tableting should provide a sufficient cushioning effect to withstand the compression force and, thereby, prevent the merging or rupturing of the microspheres.In particular, ethyl cellulose based microspheres have gained much more attention in developing controlled release microparticulate systems because of their flexibility to obtain a desirable drug release profile, cost-effectiveness, and broad regulatory acceptance. Thus, oral controlled release multiple-unit drug delivery systems, such as microspheres,microparticles, beads, and pellets have gained widespread importance due to their numerous advantages over conventional single-unit dosage forms.

\section{Materials and Methods}

\section{Materials}

Gemcitabine was obtained as a gift sample from Intas Pharmaceuticals ltd Gujarat. Ethyl cellulose and PVA was procured from SD-fine chemicals Ltd. All other ingredients used in the experiment were of analytical grade.

\section{Methods}

Preparation of Microspheres by solvent evaporation method.

Desired amount of Gemcitabine was dissolved in distilled water. Polymer (ethyl cellulose) was dissolved separately in dichloromethane and methanol in the ratio of 1:1. Then the aqueous drug solution was gradually added to aboveprepared polymeric solution with constant stirring at $600 \mathrm{rpm}$, stirring was continued forfew minutes. Then the primary emulsion was added drop by drop to PVA solution containing $2 \%$ span 80 stirring was continued up to $2 \mathrm{hr}$ at a temperature of $60^{\circ} \mathrm{c}$ in a $250 \mathrm{ml}$ glass beaker. After $2 \mathrm{hr}$ of stirring, hard, spherical microspheres were obtained. Microspheres were then washed three times with petroleum ether and vacuum-dried to obtain free flowing microspheres. 


\section{Evaluation of microspheres ${ }^{[15]}$}

\section{Micromeritic properties}

The microspheres were characterized by their micromeritic properties, such as particle size, tapped density, compressibility index and flow properties.

\section{Particle size and size distribution}

The particle size of microspheres was determined usingan optical microscopy method. The size wasmeasured using an optical microscope, and the mean particle sizewas calculated by measuring 200-300 particles with the help of acalibrated ocular micrometer.

\section{Bulk density}

Bulk density of the microspheres was calculated as the ratio between the mass of the microsphere sample (g) and itsvolume (ml) before tapping.

\section{Tapped density}

Tapped density of the microspheres was calculated as the ratio between the mass of the microsphere sample (g) and itsvolume (ml) after 100 tapping.

\section{Compressibility index}

$\%$ Compressibility index $=[1-\mathrm{V} / \mathrm{Vo}] \mathrm{X} 100$ Here $\mathrm{V}$ and Vo are the volumes of the sample after and before the standard tapping, respectively.

\section{Angle of repose}

Angle of repose of the microspheres, which measures the resistance to particle flow, was determined by a fixed funnelmethod and calculated as

$$
\tan \Theta=h / r
$$

where ' $h$ ' and' $r$ ' are standing height and radius of the microspheres heap formed on a graph paper after making themicrospheres flow from the glass funnel.

\section{Drug entrapment efficiency}

To assess drug content, $20 \mathrm{mg}$ of microspheres were weighed and dissolved in $7.4 \mathrm{pH}$ phosphate buffer solution under ultrasonication. After filtration through a whattmann filter paper and the resulting solution further diluted and Gemcitabine content was determined spectrophotometrically (UV 1800 Shimadzu, Japan) at $234 \mathrm{~nm}$. In the concentration range of $10-50 \mu \mathrm{g} / \mathrm{ml}$, the absorbance of Gemcitabine correlated well with its concentration. The percentage drug entrapment and yield of microsphere were calculated as follows:

$\%$ Drug entrapment efficiency $=[$ Experimental drug content $/$ Theoretical drug content $]$ X 100

$\%$ Yield $=[$ Total weight of microsphere $/$ Total weight of drug and polymer used $]$ X 100

\section{Drug loading efficiency}

Percent drug loading was calculated as follows:

$\%$ Drug loading $=$ [Weight of drug loaded in the microspheres /Total weight of powdered microspheres] 


\section{Surface morphology}

The surface morphology of drug loaded microspheres, blank microspheres, was examined by means of a Zeiss, Evo 40(India) scanning electron microscope.

\section{IR spectral analysis}

FT-IR analysis of pure drug, individual polymer and combination of drug and polymers in higher concentration were taken for the study. Samples were compressed with potassium bromide and transformed into disk and scanned between $4000-400 \mathrm{~cm}^{-1}$ in a SHIMADZU FT-IR (IR Affinity-1)spectrophotometer12.

\section{Tablet compression}

Out of two conventional tablet preparation methods like wet granulation ${ }^{[16]}$ and direct compression ${ }^{[17]} \mathrm{a}$ direct compression method was chosen to achieve the better tablet physical properties.

\section{Evaluation of tableted microspheres ${ }^{[18]}$}

\section{Thickness, diameter and hardness}

Thickness and diameter of the tablets were determined using Vernier caliper. Hardness or tablet crushing strength was measured using Monsanto tablet hardness tester.

\section{Weight variation test}

Twenty tableted microspheres were selected at random and average weight was determined. The individual tablets were weighed and compared with average weight. Not more than two of the individual weights deviate from the average weight of tablets by more than $5 \%$.

\section{Friability test}

The friability of tablets was determined by "Roche" friabilator. Ten tablets were taken and weighed. The tablets were subjected to the combined effects of abrasion and shock by utilizing a plastic chamber that revolves at $25 \mathrm{rpm}$ for $4 \mathrm{~min}$, dropping the tablets from a distance of six inches with each revolution. After operation, the tablets were dedusted and reweighed. The Percentage friability was determined using the formula:

$$
\text { Percentage Friability }=[(\text { Initial Weight }- \text { Final Weight }) / \text { Initial Weight }] \times 100
$$

\section{Drug content of tableted microspheres}

Each tablet was crushed into powder in a mortar and then the powder was soaked in $100 \mathrm{ml}$ of phosphate buffer solution ( $\mathrm{pH} 7.4$ ) for $24 \mathrm{hr}$ followed by sonication for $5 \mathrm{~min}$. The solution was passed through a $0.2 \mathrm{~mm}$ membrane filter (Millipore) and then the drug content was determined by measuring the absorbance at $234 \mathrm{~nm}$ using a UV spectrophotometer (Elico SL 210). Experiments were repeated in triplicate in an identical manner.

\section{In vitro drug release}

Drug release from the tabletted microspheres was studied by using a dissolution tester (Electro lab) at a stirring speed of $100 \mathrm{rpm}$. Tablets from each batch were tested using $900 \mathrm{ml}$ of dissolution medium (phosphate buffer, $\mathrm{pH} 7.4)$, maintained at $37^{\circ} \mathrm{C}$. An aliquot of the release medium $(5 \mathrm{ml})$ was withdrawn through a sampling syringe attached with $0.2 \mathrm{~mm}$ filtrate predetermined time intervals $(1,2,4,6,8,10,12,14,16,18$ and $20 \mathrm{hr})$ and an equivalent amount of fresh dissolution medium, which was prewarmed at $37^{\circ} \mathrm{C}$, was replaced. Collected samples were then analyzed for Gemcitabine content by measuring the absorbance at $234 \mathrm{~nm}$ using a UV spectrophotometer.

\section{Results and Discussion}

Gemcitabine microspheres were prepared by solvent evaporation technique with different polymeric concentrations of ethyl cellulose. Effect of different concentrations of ethyl cellulosegemcitabine microspheres were successfully examined with respect to microspheres, drug loading efficiency and release kinetics. 


\section{Surface morphology \&measurement of particle size}

In Gemcitabine microspheres, exhibited a smooth surface .When compressed, the microspheres were still intact and maintained their shape. The particle size of gemcitabine microspheres was found to be in the size range of $50 \mu \mathrm{m}$ by SEM.

Since this is an ideal requirement for producing the tableted microspheres, the procedure used in this research is suitable for tableting.

\section{Micromeritic properties}

The bulk density and tapped density was found to be in the range of $0.16 \pm 1.30$ to $0.43 \pm 2.84 \mathrm{~g} / \mathrm{cc}$ and $0.20 \pm 1.70$ to $0.521 \pm 1.94 \mathrm{~g} / \mathrm{cc}$ for all formulations. The Hausner's ratio was found in the range of $1.19 \pm 2.11 \%$ to $1.17 \pm 0.86 \%$. The carr's compressibility index was found to be between $20 \pm 1.22$ to $17.3 \pm 1.83 \%$. The angle of repose was found in the range of $19.62 \pm 0.005^{\circ}$ to $17.6 \pm 0.005^{\circ}$. It proved that the flow behaviors and compressibility of the granules are good. All the formulations showed excellent flowability as expressed in terms of micrometric parameters.

\section{Particle size and shape of microspheres}

The formulated microspheres were evaluated for the size with the aid of an optical microscope. From table the mean particle size of the ethyl cellulose microspheres at increasing ethylcellulose concentrations (i.e.at drug-polymer ratios $1: 1$ to $1: 6)$ increased from $47.6 \mu \mathrm{m}$ to $150.3 \mu \mathrm{m}$. This increase in particle size of the microspheres can be attributed to an increase in viscosity with increasing polymer concentrations, which resulted in larger emulsion droplets leads to the formation of greater microsphere size.

\section{Percentage yield}

The percentage yields of different formulations F1 to F6 were calculated and the yield was found to be in the range of $64 \%$ to $83 \%$. The loss of material during preparation of microspheres may be due to process parameters as well as during filtration of microspheres. Percentage yield of all the batches is shown in Table 4 .

\section{Estimation of drug loading and drug entrapment efficiency}

The drug loading was found to be in the range of $26.54 \%$ to $17.11 \%$ for formulations F1 to F6. The percentage encapsulation efficiency of gemcitabine microspheres in all the formulations was found to be in the range of $89.78 \%$ to $50.90 \%$. The microspheres of batch F1 showed maximum drug encapsulation of $89.78 \%$. The F6 batch microspheres showed lowest drug encapsulation of 50.90\%. From the results it was seen that as the polymer concentration increased, viscosity of the dispersed phase increased, encapsulation efficiency decreased. The percentage encapsulation efficiency, percentage drug loading was shown in Table 4 and Figure 4 shows the comparison of $\%$ drug loading of different formulations.

From the FTIR studies it was found that there was no compatibility between the drug and polymer.

The hardness of all tablet formulations was found to be in the range of $4.16 \pm 0.353 \mathrm{~kg} / \mathrm{cm}^{2}$ to $4.83 \pm 0.288 \mathrm{~kg} / \mathrm{cm}^{2}$. It indicates all the tablets have adequate mechanical strength. The accepted percentage deviation was $\pm 5 \%$ for more than $250 \mathrm{mg}$ weight tablets. The result showed that weight variation was ranging from $1047 \pm 0.957 \mathrm{mg}$ to $1010 \pm 1.154 \mathrm{mg}$. Hence the tablets complied within the IP limit in terms of uniformity of weight. In friability test the maximum weight loss should be not more than $1 \%$. The results revealed that the tablets passed the friability test. Drug content in different formulations was estimated by UV spectrophotometric method. The drug content was found in the range of $91.4 \%$ to $96.2 \%$. This indicates the drug was distributed almost uniformly throughout in all the formulations.

\section{In vitro drug release}

The in vitro drug release characteristic were studied in $\mathrm{pH} 7.4$ phosphate buffer for a period of $20 \mathrm{hrs}$ using USP XXXIII dissolution apparatus, type-II. The microsphere containing gemcitabine (F1-F6) were prepared. The results of the dissolution studies indicated that the formulations F1, F2, F3, F4, F5 and F6 released $99.23 \%, 98.43 \%, 99.49 \%, 98.42 \%, 94.48 \%$ and $86.31 \%$, of Gemcitabine at the end of $14,16,18$ and 
$20 \mathrm{hr}$ respectively (Figure 8). The change in polymer concentration may also affect the in vitro drug release mechanism of drug from the tableted microspheres. By increasing the polymer concentrations the rate of drug release was decreased due to the unavailability of drug molecules at the surface of tableted microspheres. Further, by increasing the concentration of polymer in the formulation, a point will be reached where the pores or channels formed by the drug particles within the polymer matrix were diminished. i.e., the diffusion of drug molecules from the channels of the matrix was disturbed by the increased concentration of polymer. In other words, increased polymer concentration affects the drug leaching and diffusion process from the matrix, by making it less porous and slower drug release rate occurs. The optimized formula of tableted microspheres follows zero order kinetics and from Peppas ${ }^{19}$ plot it followed anomalous non-Fickian diffusion.

Table 1:Formulation design for gemcitabine microspheres

\begin{tabular}{|c|c|c|}
\hline Formulation code & Drug(gm) & Polymer $(\mathbf{g m})$ \\
\hline AF1 (1:0.5) & 5 & 2.5 \\
\hline AF2 (1:1) & 5 & 5 \\
\hline AF3 (1:1.5) & 5 & 7.5 \\
\hline AF4 (1:2) & 5 & 10 \\
\hline AF5 (1:2.5) & 5 & 12.5 \\
\hline AF6 (1:3) & 5 & 15 \\
\hline
\end{tabular}

Table 2: Formulation design of gemcitabine tableted microspheres

\begin{tabular}{|l|c|c|c|c|c|c|}
\hline Ingredient & CF1 & CF2 & CF3 & CF4 & CF5 & CF6 \\
\hline Gemcitabine microspheres Eq. to 200mg & 300 & 400 & 500 & 600 & 700 & 800 \\
\hline Mg. stearate & 10 & 10 & 10 & 10 & 10 & 10 \\
\hline MCC & 350 & 300 & 250 & 200 & 150 & 100 \\
\hline Lactose & 340 & 290 & 240 & 190 & 140 & 90 \\
\hline Total (mg) & 1000 & 1000 & 1000 & 1000 & 1000 & 1000 \\
\hline
\end{tabular}

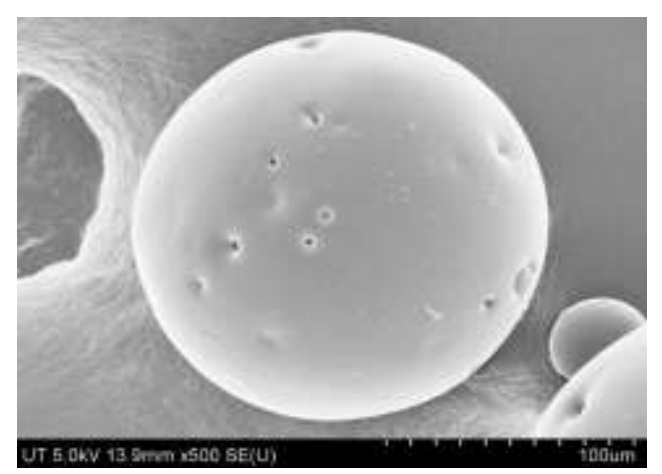

Figure 1:SEM photograph of blank ethyl cellulosemicrosphere

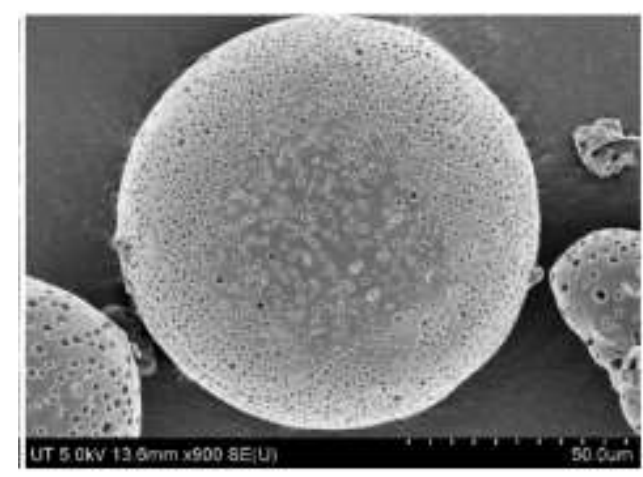

Figure 2: SEM Photograph of gemcitabine microsphere 
Table 3:Particle size data of gemcitabine microspheres

\begin{tabular}{|c|c|c|}
\hline S. No. & Formulation code & Average size $(\boldsymbol{\mu m})$ \\
\hline 1 & AF1 & $47.6 \pm 2.73$ \\
\hline 2 & AF2 & $76.0 \pm 6.53$ \\
\hline 3 & AF3 & $99.8 \pm 8.62$ \\
\hline 4 & AF4 & $107.2 \pm 9.97$ \\
\hline 5 & AF5 & $113.1 \pm 7.17$ \\
\hline 6 & AF6 & $150.3 \pm 5.32$ \\
\hline
\end{tabular}

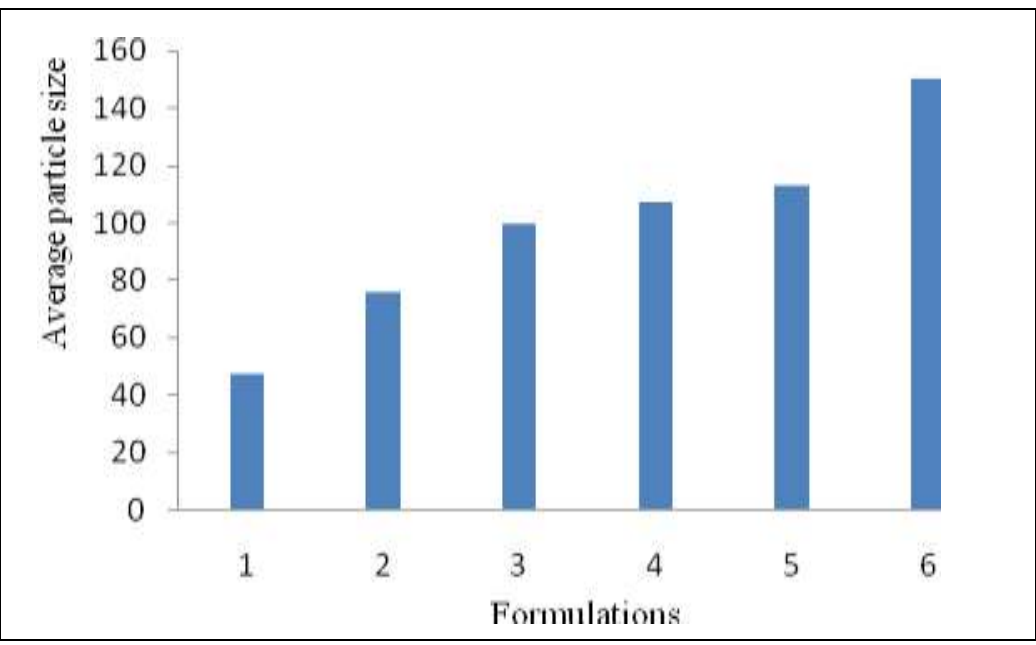

Figure 3: Particle size of gemcitabine microspheres

Table 4:Data for drug entrapment efficiency of gemcitabine microspheres

\begin{tabular}{|c|c|c|c|c|}
\hline S. No. & $\begin{array}{c}\text { Formulation } \\
\text { code }\end{array}$ & \% yield & $\begin{array}{c}\text { \% Drug } \\
\text { loading }\end{array}$ & $\begin{array}{c}\text { Entrapment efficiency } \\
\text { (\%) }\end{array}$ \\
\hline 1 & AF1 & 83.22 & 26.54 & 89.78 \\
\hline 2 & AF2 & 80.43 & 23.42 & 84.82 \\
\hline 3 & AF3 & 76.35 & 21.89 & 66.34 \\
\hline 4 & AF4 & 72.83 & 20.53 & 58.80 \\
\hline 5 & AF5 & 68.87 & 18.29 & 51.88 \\
\hline 6 & AF6 & 64.98 & 17.11 & 50.90 \\
\hline
\end{tabular}

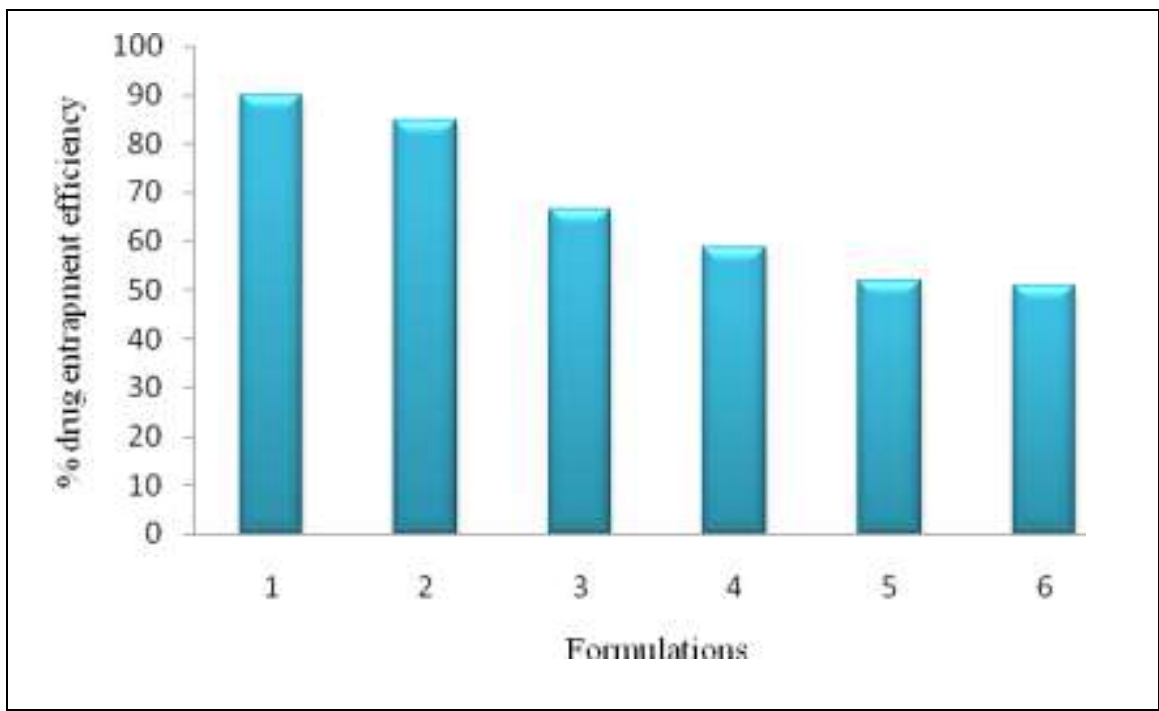

Figure 4:Drug entrapment efficiency of gemcitabine microspheres 


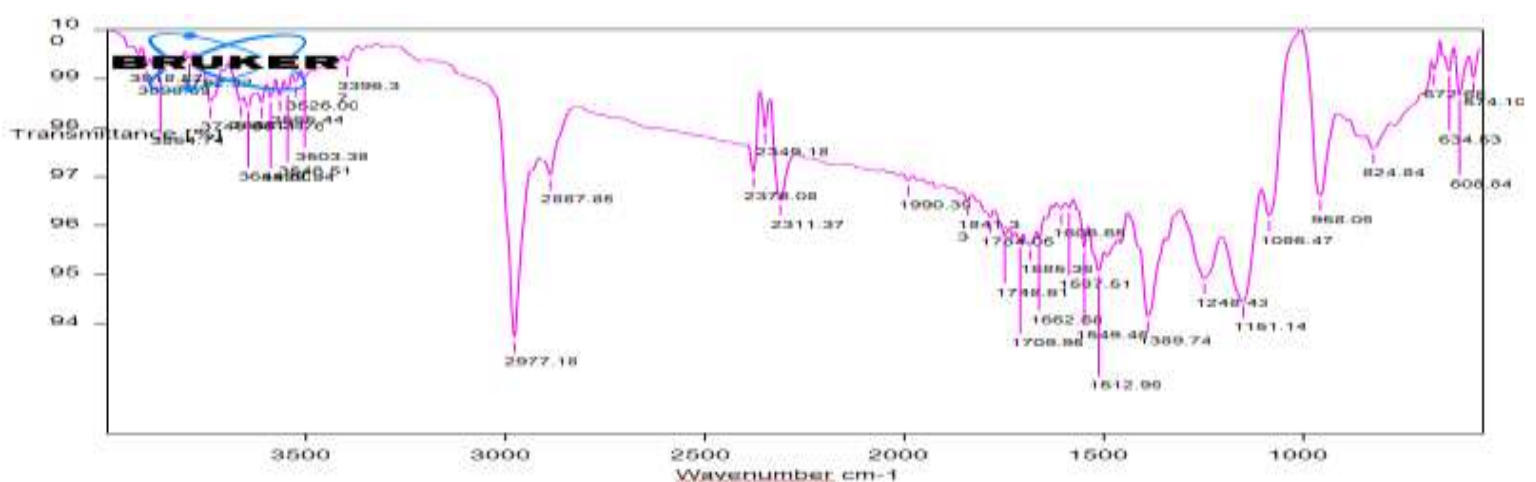

Figure 5: IR Spectrum of gemcitabine

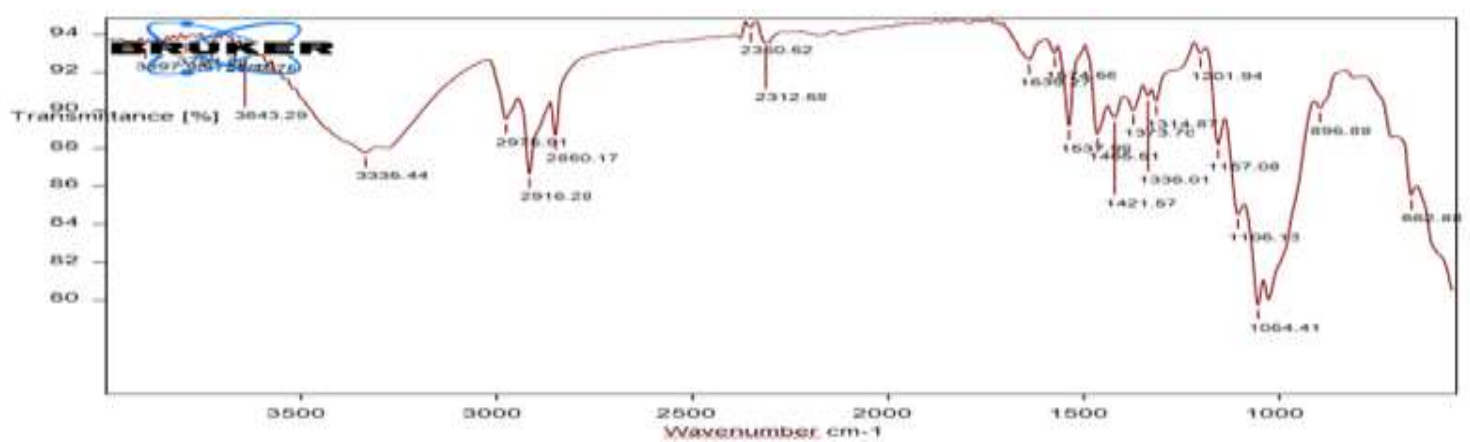

Figure 6: IR spectrum of blank ethyl cellulose microspheres

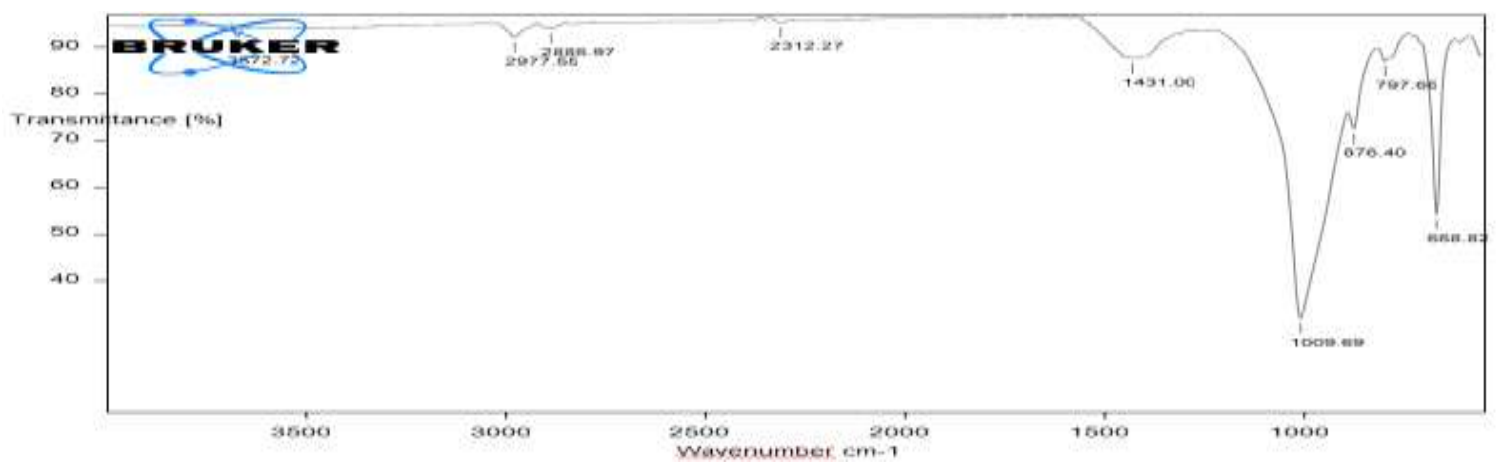

Figure 7: IR spectrum of gemcitabine microspheres

Table 5:Evaluation parameters of gemcitabine tableted microspheres

\begin{tabular}{|c|c|c|c|c|c|}
\hline $\begin{array}{l}\text { S. } \\
\text { No. }\end{array}$ & $\begin{array}{c}\text { Formulation } \\
\text { code }\end{array}$ & $\begin{array}{c}\text { Hardness } \\
\left(\mathbf{k g} / \mathbf{c m}^{2}\right) \\
(\mathbf{n}=5)\end{array}$ & $\begin{array}{c}\text { Weight variation } \\
(\mathrm{mg}) \text { mean } \\
\pm \mathrm{S} . \mathrm{D}(\mathrm{n}=10)\end{array}$ & Friability (\%) & $\begin{array}{c}\text { Drug content } \\
(\%)\end{array}$ \\
\hline 1 & $\mathrm{AF} 1$ & $4.16 \pm 0.353$ & $1047 \pm 0.957$ & $0.227 \pm 0.01$ & 91.4 \\
\hline 2 & AF2 & $4.16 \pm 0.288$ & $1007 \pm 1.78$ & $0.26 \pm 0.03$ & 92.2 \\
\hline 3 & AF3 & $3.83 \pm 0.288$ & $1001 \pm 0.017$ & $0.17 \pm 0.05$ & 94.1 \\
\hline 4 & $\mathrm{AF} 4$ & $4.66 \pm 0.288$ & $1065 \pm 1.09$ & $0.15 \pm 0.03$ & 94.6 \\
\hline 5 & AF5 & $4.16 \pm 0.353$ & $1004 \pm 0.659$ & $0.21 \pm 0.01$ & 95.3 \\
\hline 6 & AF6 & $4.83 \pm 0.288$ & $1010 \pm 1.154$ & $0.20 \pm 0.02$ & 96.2 \\
\hline
\end{tabular}


Table 6:Zero order kinetic data of gemcitabine tableted microspheres

\begin{tabular}{|c|c|c|c|c|c|c|c|}
\hline \multirow{2}{*}{ S. No } & \multirow{2}{*}{ Time (hr) } & \multicolumn{7}{|c|}{ \% Drug released } \\
\cline { 3 - 7 } & & CF1 & CF2 & CF3 & CF4 & CF5 & CF6 \\
\hline 1 & 0 & 0 & 0 & 0 & 0 & 0 & 0 \\
\hline 2 & 1 & 31.92 & 21.97 & 14.23 & 13.48 & 10.68 & 7.43 \\
\hline 3 & 2 & 41.35 & 29.44 & 26.35 & 24.62 & 14.98 & 11.43 \\
\hline 4 & 4 & 63.11 & 40.53 & 34.48 & 33.28 & 24.61 & 17.82 \\
\hline 5 & 6 & 68.78 & 54.51 & 45.01 & 42.04 & 32.3 & 22.36 \\
\hline 6 & 8 & 71.89 & 68.38 & 56.39 & 53.55 & 43.12 & 38.02 \\
\hline 7 & 10 & 84.21 & 81.39 & 68.51 & 65.09 & 58.76 & 46.52 \\
\hline 8 & 12 & 94.71 & 86.43 & 76.46 & 72.58 & 67.34 & 58.68 \\
\hline 9 & 14 & 99.23 & 92.67 & 84.38 & 81.45 & 75.92 & 65.34 \\
\hline 10 & 16 & - & 98.43 & 93.84 & 90.86 & 83.56 & 76.61 \\
\hline 11 & 18 & - & - & 99.49 & 94.79 & 90.64 & 82.84 \\
\hline 12 & 20 & - & - & - & 98.42 & 94.48 & 86.31 \\
\hline
\end{tabular}

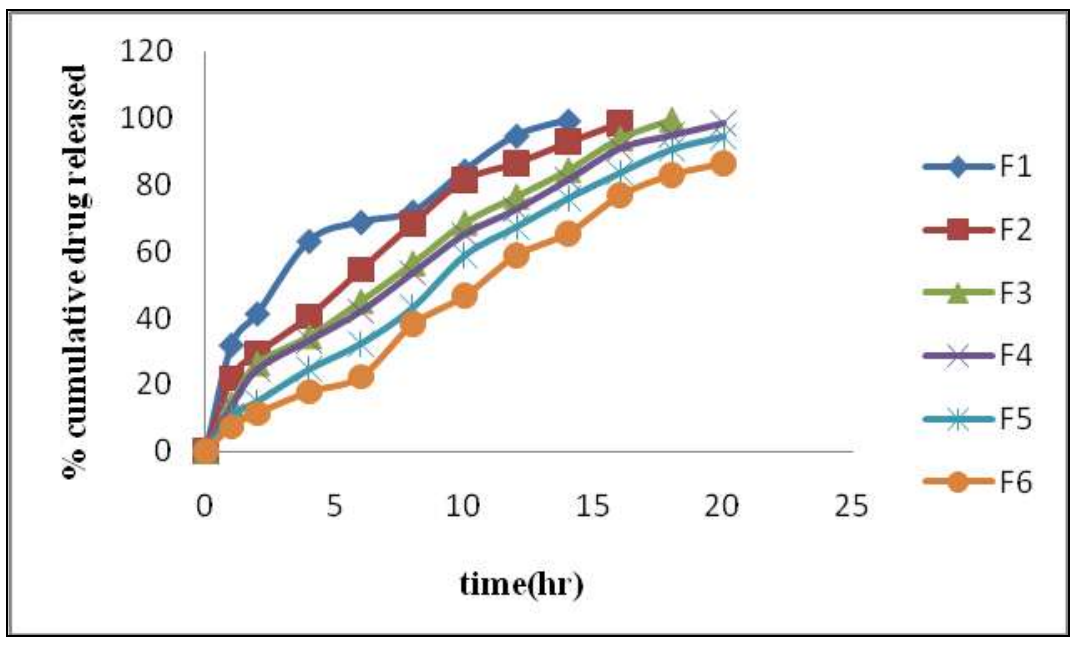

Fig : 8 Comparative in vitro release profile of gemcitabine loaded tabletted microspheres

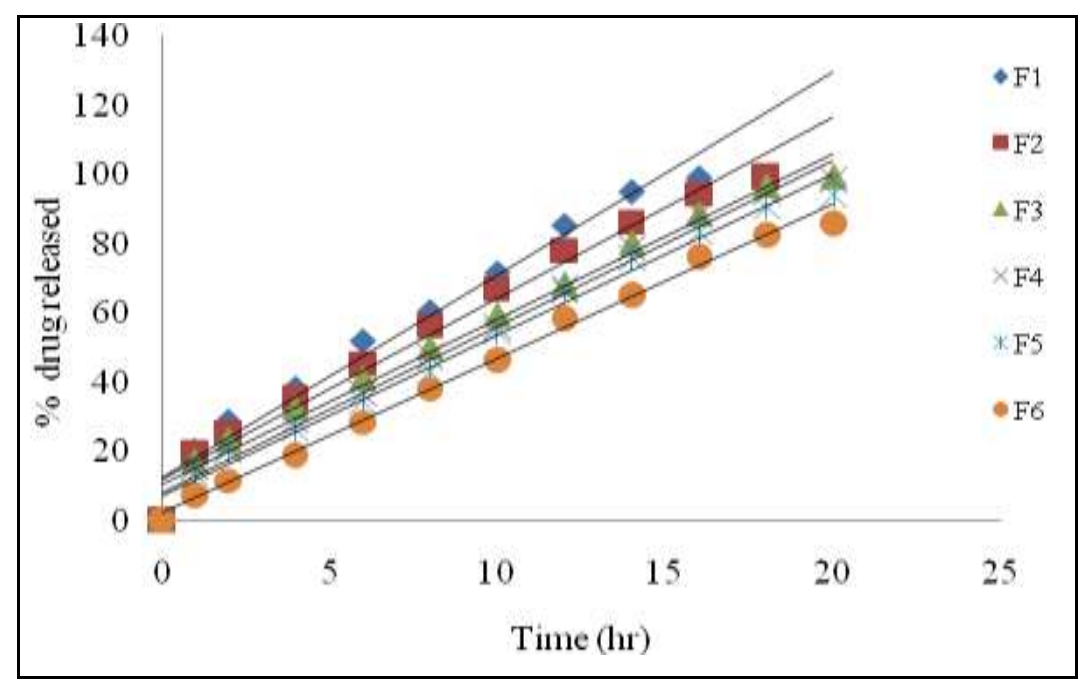

Figure 9: Zero order kinetic release for gemcitabine tableted microspheres 


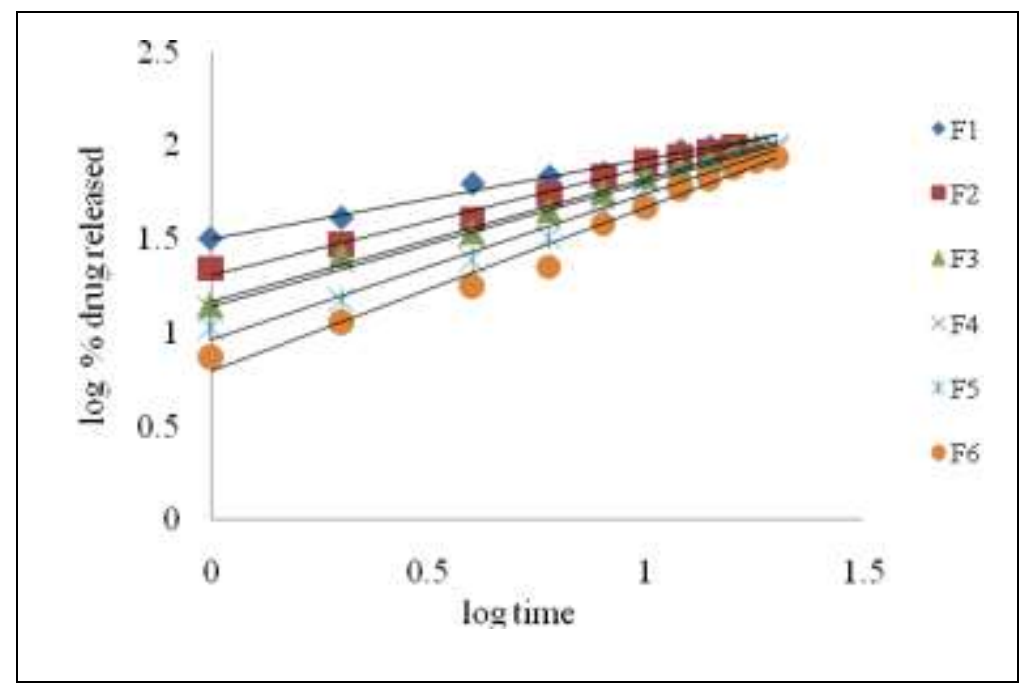

Figure 10:Peppas kinetics release gemcitabine tableted microspheres

\section{Conclusion}

This study elaborated that the solvent evaporation technique is an appropriate method to microencapsulate gemcitabine into the ethyl cellulose coats. It could be concluded that the variation observed in entrapment efficiency, mean particle size and the drug release behavior among the formulations are the result of the drug polymer ratio employed. These results may suggest the potential application of ethyl cellulose microspheres in to tablets of formulation CF5 as a suitable controlled release drug delivery system. The optimized formula of tableted microspheres follows zero order kinetics and from Peppas plot it followed anomalous non-Fickian diffusion.

\section{References}

1. Alonso, M. J., Gupta, R. K., Min, C., Siber, G. R., \& Langer, R. (1994). Biodegradable microspheres as controlled-release tetanus toxoid delivery systems. Vaccine, 12(4), 299-306. doi:10.1016/0264410X(94)90092-2.

2. Saralidze, K., Koole, L. H., \& Knetsch, M. L. W. (2010). Polymeric Microspheres for Medical Applications. Materials (Basel), 3(6), 3537-3564. doi:10.3390/ma3063537.

3. Muggia, F., Diaz, I., \& Peters, G. J. (2012). Nucleoside and nucleobase analogs in cancer treatment: not only sapacitabine, but also gemcitabine. Expert Opinion on Investigational Drugs, 21(4), 403-408. doi:10.1517/13543784.2012.666236.

4. https://www.drugbank.ca/drugs/DB00441

5. https://pubchem.ncbi.nlm.nih.gov/compound/gemcitabine

6. Rawat, S., Bisht S., Kothiyal P. (2013). Characterization and release kinetics of microspheres and tableted microspheres of diclofenac sodium. American Journal of Advanced Drug Delivery, 1(4), 596605.

7. Kwon, G. S., \& Furgeson, D. Y. Biodegradable polymers for drug delivery systems. Biomedical Polymers, Chapter 4, A volume in Woodhead Publishing Series in Biomaterials, 2007; 83-110.

8. Arregui, J. R., Kovvasu, S. P., \& Betageri, G. V. (2018). Daptomycin proliposomes for oral delivery: Formulation, characterization, and in-vivo pharmacokinetics. AAPS PharmSciTech, 19(4), 1802-1809. doi:10.1208/s12249-018-0989-0.

9. Junyaprasert, V. B., Mitrevej, A., Sinchaipanid, N., Boonme, P., \& Wurster, D. E. (2001). Effect of process variables on the microencapsulation of vitamin A palmitate by gelatin-acacia coacervation. Drug Development and Industrial Pharmacy, 27(6), 561-566. doi:10.1081/DDC-100105181.

10. Patel, A. S., Soni, T., Thakkar, V., \& Gandhi, T. (2012). Effects of spray drying conditions on the physicochemical properties of the tramadolHCl microparticles containing Eudragit ${ }^{\circledR}$ RS and RL. Journal of Pharmacy \& Bioallied Sciences, 4(5, Suppl 1), 50-S53. doi:10.4103/0975-7406.94134. 
11. Chowdary, K. P. R., Sundari, P. T., \& Prakasarao, K. S. (2009). Formulation and evaluation of piroxicam and aceclofenac tablets employing Prosolve by direct compression method. Asian Journal of Chemistry, 21(8), 5847-5850.

12. Chowdary, K. P. R., Prakasarao, K. S., \& Madhuri, D. (2011). Formulation and evaluation of etoricoxib tablets employing cyclodextrin- Poloxamer 407- PVP K30 inclusion complexes. International Journal of Applied Biology and Pharmaceutical Technology, 2(4), 43-48.

13. Chowdary, K. P. R., Prakasarao, K. S., \& Amar, A. (2012). A factorial study on the effects of cyclodextrins, Poloxamer 407 and PVP on the solubility and dissolution rate of valsartan. International Journal of Pharmacy and Pharmaceutical Sciences, 4(1), 285-287.

14. Kovvasu, S. P., Kunamaneni, P., \& Janjanam, K. C. (2016). Formulation and optimization of controlled release paroxetine hydrochloride tablets using response surface methodology. Journal of Global Trends in Pharmaceutical Sciences, 7, 3520-3534.

15. Venkatesh, D. P., \& Roopa, K. (2012). SajalKJ, GeethaLA, Santha Kumar GS, DivakarGoli. Formulation and evaluation of microspheres containing fluvastatinsodium. International Journal of Drug Development and Research, 4(2), 306-314.

16. Chowdary, K. P. R., \& Prakasarao, K. S. (2011). Formulation development of pioglitazone tablets employing $\beta$ cyclodextrin-Poloxamer 407-PVP K30: A factorial study. Der Pharmacia Lettre, 3(6), 24 30.

17. Chowdary, K. P. R., Sundari, P. T., \& Prakasarao, K. S. (2008). Formulation and evaluation of piroxicam and celecoxib tablets employing Prosolve by direct compression method. International Journal of Chemical Sciences, 6(3), 1270-1275.

18. Shah, S., Madan, S., \& Agrawal, S. S. (2012). Formulation and evaluation of microsphere based oro dispersible tablets of ItoprideHCl. Daru : Journal of Faculty of Pharmacy, Tehran University of Medical Sciences, 20(1), 24. doi:10.1186/2008-2231-20-24.

19. Ritger, P. L., \& Peppas, N. A. (1987). A simple equation for description of solute release I. Fickian and non-fickian release from non-swellable devices in the form of slabs, spheres, cylinders or discs. Journal of Controlled Release, 5(1), 23-36. doi:10.1016/0168-3659(87)90034-4. 